\title{
Metal-Phthalocyanine Functionalized CNTs Sensor for Chloroform Series
}

\author{
Swasti Saxena $^{1}$, Ankit Kumar Srivastava ${ }^{2}$,Ruchi Srivastava ${ }^{3}$ and Vipul Kheraj ${ }^{4}$ \\ ${ }^{1}$ Discipline of Metallurgy Engineering and Materials Science, Indian Institute of Technology \\ Indore, Indore (India)-453552. \\ ${ }^{2}$ Department of Physics, Indian Institute of Technology Bombay, Mumbai (India)-400076. \\ ${ }^{3}$ Amity Institute of Applied Sciences, Amity University Noida sector 125(India)-301201. \\ ${ }^{4}$ Applied Physics Department, Sardar Vallabhbhai National Institute of Technology, Surat \\ (India)-395007.
}

\begin{tabular}{l} 
ARTICLE INFO \\
\hline Keywords: \\
Chemical vapour sensor, \\
Metal-phthalocyanine, \\
Thin films, \\
Functionalized Carbon \\
nanotubes.
\end{tabular}

\section{ABSTRACT}

In this paper, We report fabrication of sensors from multiwalled carbon nanotube (MWCNT) functionalized with metalphthalocyanines (M-Pc or $\mathrm{Cu}-\mathrm{Phs}$ ). We made very sensitive ans selective sensor for Chloroform. We had characterized the material using FTIR and TEM techniques. We inferred that the metal-Pc form nanoclusters around the surface of f-MWNTs and the sensors prepared from these materials show resistivity in the kilo-ohm range. Our sensors show sensing capability of $100 \mathrm{ppm}$ and the response as well as recovery times of few seconds. We observed interesting behaviour of the sensors made from M-Pc on exposure to chloroform $(\mathrm{CHCl} 3)$ vapours while for many other vopours like carbon tetra chloride $(\mathrm{CCl} 4)$, dichloromethane $(\mathrm{CH} 2 \mathrm{Cl} 2)$, clorine water $(\mathrm{Cl} 2)$ showed opposite results after the exposure on these sensors. We shall discuss the differences in the response and recovery time, and mechanism of sensing for chloroform and other vapours.

\section{Introduction}

According to the U.S. National Institute for Occupational Safety and Health, Chlorinate compounds are frequently used in a wide range of industrial products and chemical processes. Chlorinated aliphatic hydrocarbons such as $\mathrm{CCl}_{4}, \mathrm{CHCl}_{3}$, and $\mathrm{CH}_{2} \mathrm{Cl}_{2}$ are important source to environment pollutants (Kylin B et al. 1963). They are introduced mainly from their use as solvents in paints, adhesives, degreasers, colour removers or related products. These chlorinated organic solvent can cause severe health effects such as irritation, lung congestion, kidney and liver damage, effect on brain, and cancer. Among of these chlorinated compounds, chloroform $\left(\mathrm{CHCl}_{3}\right)$ is considered a more dangerous to health and life (Anna M, 2005]. Chloroform was widely used anaesthetic, and is used as a solvent in the pharmaceutical industry and for producing dye and pesticides (Jones WM et al. 1958.) Chloroform is a central nervous system depressant which can 
also cause respiratory and cardiac failure with sufficient exposure(Ikatsu $\mathrm{H}$ and Nakajima T. 1992). Breathing about $1000 \mathrm{ppm}$ for a short time can cause dizziness, fatigue, and headache. Therefore, there is a high demand on deployment of portable, cheaper gas detectors at work place for real time monitoring the levels of chloroform so that precaution can be taken in the presence of this toxic gas. Its use in consumer products is therefore mostly phased out Like Carbon Tetrachloride, it saw use as a refrigerant and cleaning solvent. It was also used as a surgical anesthetic, but the aforementioned toxicities led to an unacceptably high fatality rate. Its use in medical applications has been discontinued in favor of safer alternatives.

Most of the chloroform found in the environment comes from industry. Chloroform has a multitude of natural sources, both biogenic and abiotic (Kanada M et al. 1994). It is estimated that greater than $90 \%$ of atmospheric chloroform is of natural origin. Researchers have designed a new kind of sensor that can detect minute traces of chloroform in various biological and environmental samples. The sensor was made from a polymer nanocomposite consisting of organic-acid-modified multi-walled carbon nanotubes (Sharma et al, 2002). Many scientist in the past have reported detection of $\mathrm{CHCl}_{3}$ by employing mainly electrochemical anodization process, carbon nanotubes [rehman et al ,2016) and many other alternatives including calorimetric (Sheng K et al, 2019), chemi-resister (Abraham, 2004; Feller et al 2014, Sharma et al 2018) and biosensors based methods [Mondal, 2013]. Recent developments in fibre optical chemical sensors (FOCs) (Giordano et al, 2005; Jonathan 2015) offer real time monitoring of volatile chlorinated hydrocarbons in water (Jo WK, et al. 1990), where the contact of chlorinated hydrocarbos with fluorescent indicator immobilized in polymer film cause change in fluorescence intensity. Several other methods like laser-induced fluorescence, gas chromatography and solid phase micro-extension are available to determination of chlorinated hydrocarbons. However, these techniques are very much complicated, expensive and laborious. Hence, a viable gas-sensing element with low detection limit must be developed for selective detection of chloro-hydrocarbon gas under ambient condition. Recently, polymer based chemical sensor offer real time monitoring of volatile chlorinated hydrocarbon in air and water.

Phthalocyanines (Pc) and their metal derivatives are p-type semiconductors and have been widely used as gas sensor [Philip et al., 2003; sharma et al., 2017]. During recent past, vacuum deposited thin films of metal-phthalocyanine (MPc) have been utilized for detection of $\mathrm{CHCl}_{3}$ and other vapors. Carbon nanotubes (CNTs) based sensor have received considerable attention because of their outstanding properties, including high aspect ratio, and excellent chemical and environmental stability, which make them ideal candidate for the detecting toxic gases. The principle for CNT gas sensors for the detection and quantization of gases are based on changes in electrical properties induced by charge transfer with the gas molecule or change in the adsorption, Although, the sensitivity and selectivity of pristine CNT toward gases is limited due to the weak interaction and minimum charge transfer between the CNT and the gas molecule (Kanan at el 2009).

The improvement of interfacial interaction can be achieved by the surface-functionalization of nanotube. The extended pi electronic system of CNTs makes them very attractive for manipulating charge transfer when combined with strong electron acceptors like metal phthalocyanines (M-Pc) or tetra phenyle porphyrin. It is expected that functionalized MWCNT with metal phthalocyanines may overcome the problem of very low electrical conductivity of thin film of MPc. We therefore adopted an approach to prepare the composite material which may lead to better opportunity for vapor sensing by exploiting the unique sensing abilities of MPc in combination with the high electrical conductivity of CNTs (Kar \& Choudhury,2013). 
Figure 1: (a) Porphyrin (b) Metal phthalocyanine (M-Pc) (c) Metal-Tetraphenyle porphyrin (M-TPP)

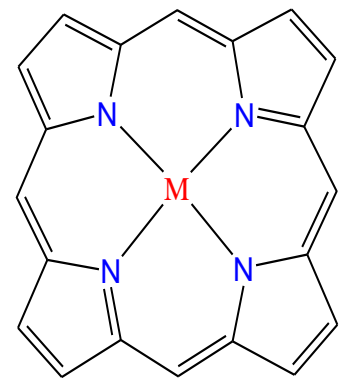

Metal Porphyrin

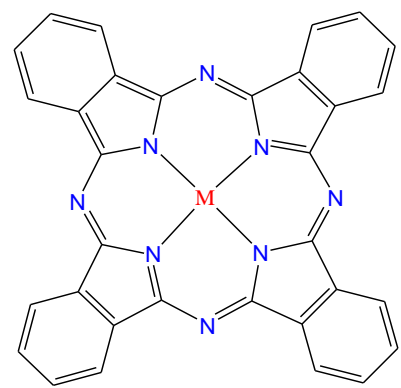

Metal-Phthalocyanine

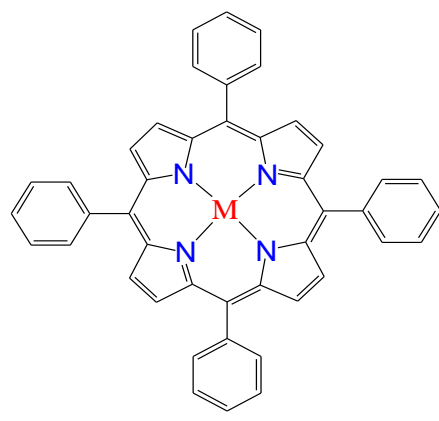

Metal-Tetraphenylporphyrin

The present work proposes the MPc/ f-MWCNT nanocomposite based pair sensors for selective detection of chloroform at room temperature. A combination of sensors made from composites of cobalt-phthalocyanine (Co-Pc) and copper-phthalocyanine $(\mathrm{Cu}-\mathrm{Pc})$ with f-MWCNT. The responses of these composites for different organic vapors were evaluated by monitoring the change in the resistance of thin film of composite when exposed to gases. It was observed that the CNT/MPcs showed the higher and selective response. Sensor response toward chloroform was tested, and the result shows that MPc/ f-MWCNT array has the good response and high reproducibility at ambient condition.

\section{Experimental Details}

\subsection{Materials}

The multi-walled carbon nanotube (purity 95\%, diameter $=10-15 \mathrm{~nm}$, length $=0.1-10 \mathrm{~mm}$, density=1.7-2.1 g/ cm3), Metal Phthalocyanine were procurred from Sigma Aldrich. Chloroform (purity $>=99.8 \%$ ) , $\mathrm{CCl}_{4}$, and dichloromethan $\mathrm{CH}_{2} \mathrm{Cl}_{2}$ and chlorine water was purchased from M/S Qualigen Fine Chemical, India. Same materials were used for all the experiments reported in this study. The samples of f-MWCNTs, MPcs and prepared composites were diluted in $\mathrm{KBr}$ matrix to measure FTIR spectra

\subsubsection{Prepartion of composites and Sensors}

To begin with, the pristine MWNTs were functionalized by corona electrostatic discharge which resulted in the grafting of $-\mathrm{OH}$ groups to the end faces and defect sites on the walls of MWNTs (Léger et al., 2002). This is confirmed by the presence of bands around 3457 and $1637 \mathrm{~cm}^{-1}$ in the FTIR spectra of f-MWNTs resulting from O-H stretching and deformation modes respectively as shown in Fig. 2 a. We shall denote the -OH functionalized MWNTs as f-MWNTs. The active-OH groups on f-MWNTs facilitate H-bonding, $\pi$ - $\pi$ and other non-covalent interactions with M-Pc.

In a typical procedure, $10 \mathrm{mg}$ of f-MWCNT was suspended in $50 \mathrm{ml}$ toluene and sonicated for 1 hour to disperse MWCNT properly. Weighed quantity of $\mathrm{CuPc}$ or $\mathrm{CoPc}$ were added to the dispersed MWCNT and magnetically stirred for 24 hours at $60{ }^{\circ} \mathrm{C}$ temperature followed by ultrasonification for 30 min to obtain composite. The resistivity of prepared samples depends on the relative quantities of MPc and f-MWCNT so we utilized those nanocomposite samples which showed resistance in the 100 
to $300 \mathrm{ohm}$ range. The nanocomposite solution consists of $5 \mathrm{mg}$ of $\mathrm{f}-\mathrm{MWCNT}$ and $50 \mathrm{mg}$ of M-Pc in ethanol solvent. A small drop of the nano-composite slurry on a glass plate was spread into an uniform film anchored by paraffin film. The upper surface of the film was covered by another paraffin film and sandwiched by placing a glass plate on the top of the film. The whole system was kept inside an oven at a temperature of $70^{\circ} \mathrm{C}$ and heated for $\sim 5$ minutes. Sufficient care was taken to ensure that the paraffin got embedded only in the upper surface of the film of slurry which provided stability to the film. The other side of the film, not affected by the paraffin, was used to make electrical contacts using conducting silver paste for measurements. The schematic diagram of the process for fabrication is given in Fig. 2b. These films showed good stability and could be used many times over a period of several months with high reproducibility.

Figure 2: (a) functionalisation process through corona electrostaic discharge techmique (b) preparation steps for sensor
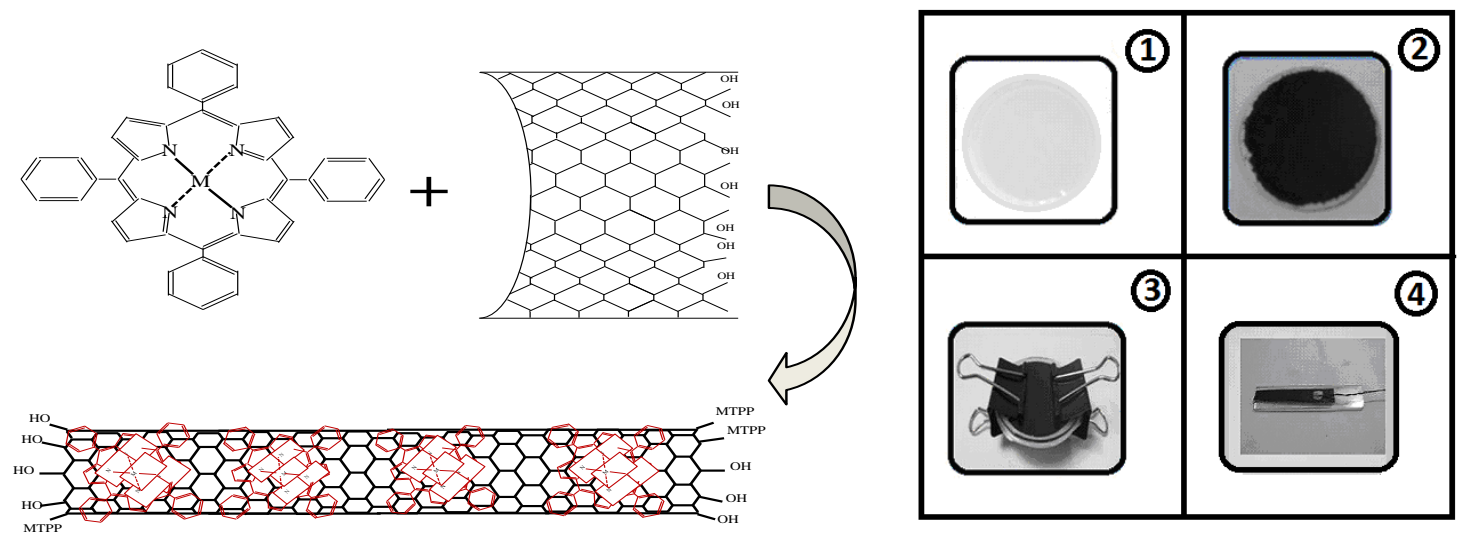

\subsubsection{Measurements}

The experimental setup for measuring the change in electrical response of the sensors on exposure Chloroform vapors is shown in Figure 3.

Figure 3: Schematic diagram of experimental setup for sensing chloroform vapors CuPc or CoPc functionalized MWNTs film.

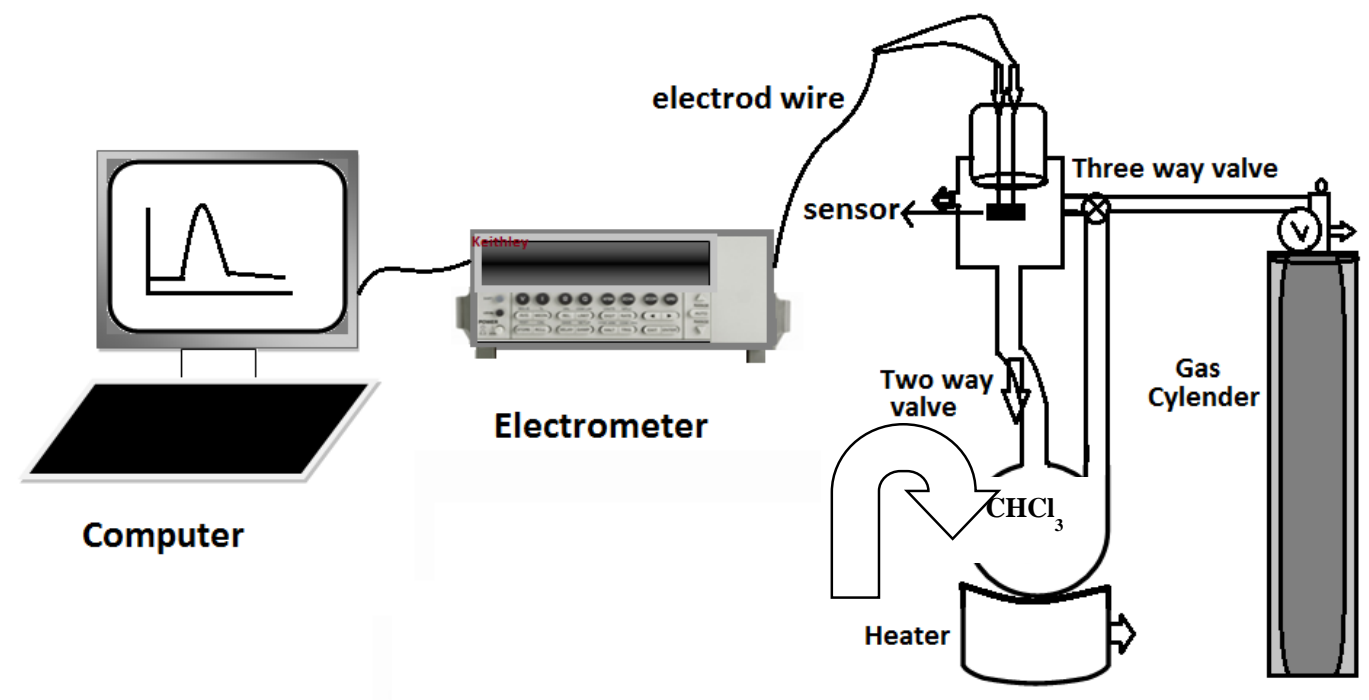


Known quantities of chemicals were introduced in the glass flask of $500 \mathrm{ml}$ capacity, heated slightly so that the chemicals converted into vapors. The chamber could also be purged with controlled flow of dry nitrogen gas at the flow rate of $70 \mathrm{ml} / \mathrm{sec}$ via a three-way valve. The valves allowed the control of flow of gas to be switched from inert nitrogen gas to known concentrations of Chloroform vapors at almost the same pressure and flow rate. The gas sensitive characteristics of the composites as sensor were investigated at ambient conditions by recording their electrical responses when exposed alternately to the purified $\mathrm{N}_{2}$ gas which was used as a reference and purging gas and chemical vapors under investigation. Based on partial pressure of gases and flow rate of nitrogen gas, we estimate the concentration of chloroform in the $100 \mathrm{ppm}$ range. The outlet for chemical vapors was closed after one second, purged with nitrogen gas to allow the resistance of the sensor to recover. Before starting another experiment, the chamber was cleaned and nitrogen gas was passed over the sample to remove the traces of initial chemical. The electrical current and resistance of the thin films were measured by a volt-amperometric technique using Keithley Model 6517B electrometer interfaced with a computer to store and process the data (Saxena at el 2014)

\section{Results and discussion}

The samples of f-MWNTs and M-Pc prepared composites were diluted in $\mathrm{KBr}$ matrix to measure FTIR spectra on a Perkin-Elmer Model PE-Rx1 FTIR spectrometer having spectral resolution of $2 \mathrm{~cm}^{-1}$ and Transmission electron microscopy (Hitachi Model H-7650 operated at 100 $\mathrm{kV}$ ), were utilized to get detailed information about the surface morphology of the prepared composites. The deionized (DI) water was used for the synthesis and washing purpose.

\subsection{FTIR spectra}

Fig.4. FTIR spectra of $M-P c, f-M W C N T$ and $M-P c / f-M W C N T$

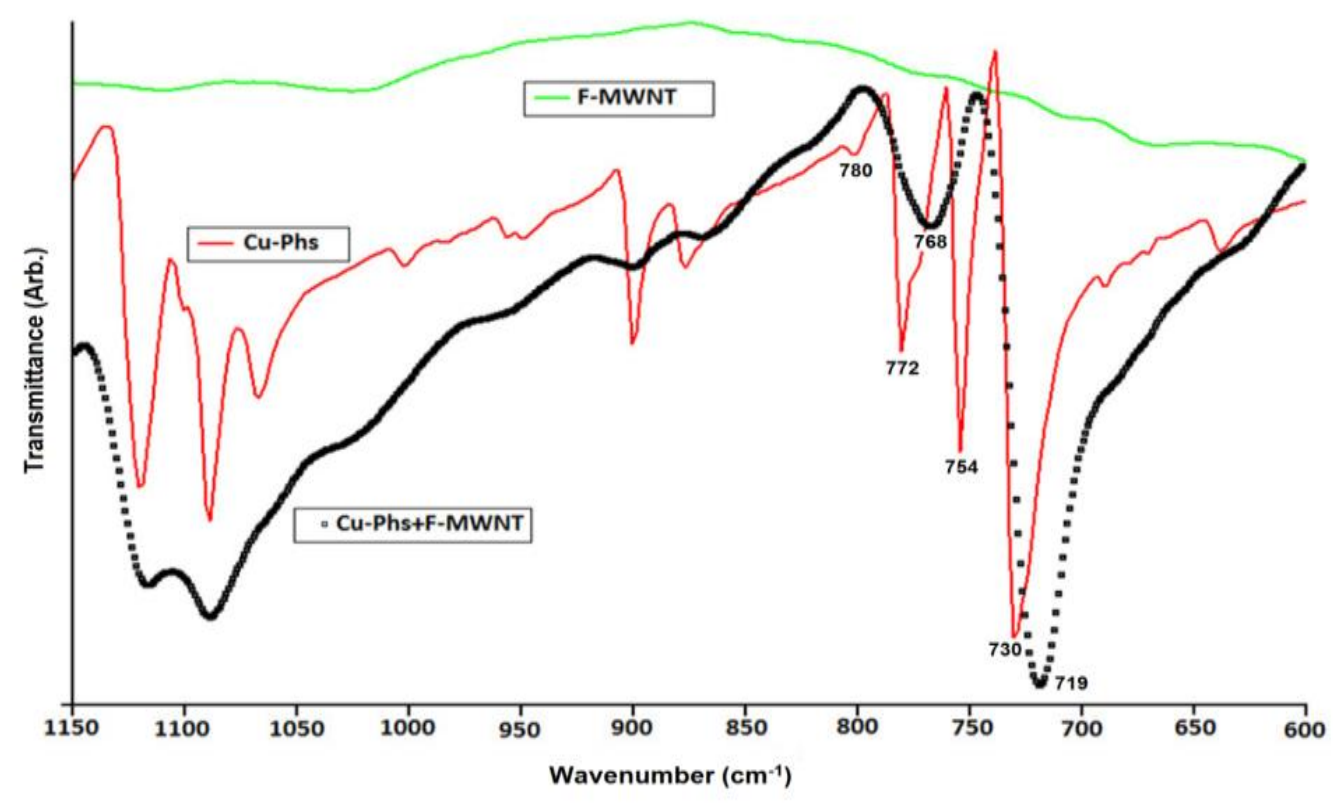


The FTIR spectra of f-MWCNT, M-Pc (Cu-Phs) and M-Pc/ f-MWCNT nanocomposite are shown in Fig. 4 [A.L.verma et al, 2011]. Important bands showing frequency shift or intensity changes are marked. A comparison of the IR spectra shows that bands related to the $-\mathrm{OH}$ groups at $\sim 3457$ and $1637 \mathrm{~cm}^{-1}$ in the spectrum of f-MWCNT's become very weak on functionalization with Cu-Pc [ H. Pan, et al,2003; J. Wang et al, 2002; X. Yu et al 2003). There are drastic changes in the IR spectrum of f-MWNTs + Cu-Pc compared to spectrum of pure $\mathrm{Cu}-\mathrm{Pc}$. The peak intensities are decreased in nanocomposites as compared to pure MPc. This happens because of MPc monomer are absorbed onto the surface of f-MWCNT. There are drastic changes in the IR spectrum of f-MWCNT+ CuPc composite compared to the spectrum of pure $\mathrm{CuPc}$. The IR spectra of pure $\mathrm{CuPc}$ are typical signatures of the beta- form and all the observed bands have recently been assigned by singh et al. On the other hand, the IR spectrum of f-MWCNT+ CuPc composite shows considerably shift in the position of many bands and most of the bands broaden considerably compared to the spectrum of the pure CuPc powder. The IR bands in 700 to $800 \mathrm{~cm}-1$ region are very sensitive and are often used to identify different polymorphs of MPc due to their sensitivity to the specific crystal packing arrangements in different form. Out of these forms, $\underline{\alpha}$ is a metastable form while $\beta$ is a stable form of CuPc. The specific signatures of the presence of $\beta$ form of $\mathrm{CuPc}$ in the powder form are the IR bands at 730,754, 772 and $780 \mathrm{~cm}-1$. On the other hand, only two IR bands are observed in the spectrum of CuPc $+\mathrm{f}-\mathrm{MWCNT}$ composite at 719 and $768 \mathrm{~cm}-1$ which confirms that the $\mathrm{CuPc}$ having $\beta$ - form has converted into $\alpha$-form. This interesting conversion to different polymorphs on interactions with f-MWCNT has been found to depend on preparation condition and other process parameter. Here we focus on the sensing aspects of this composite for the detection of $\mathrm{CHCl}_{3}$ another chemical vapour. 


\subsection{Transmission Electron microscopy (TEM)}

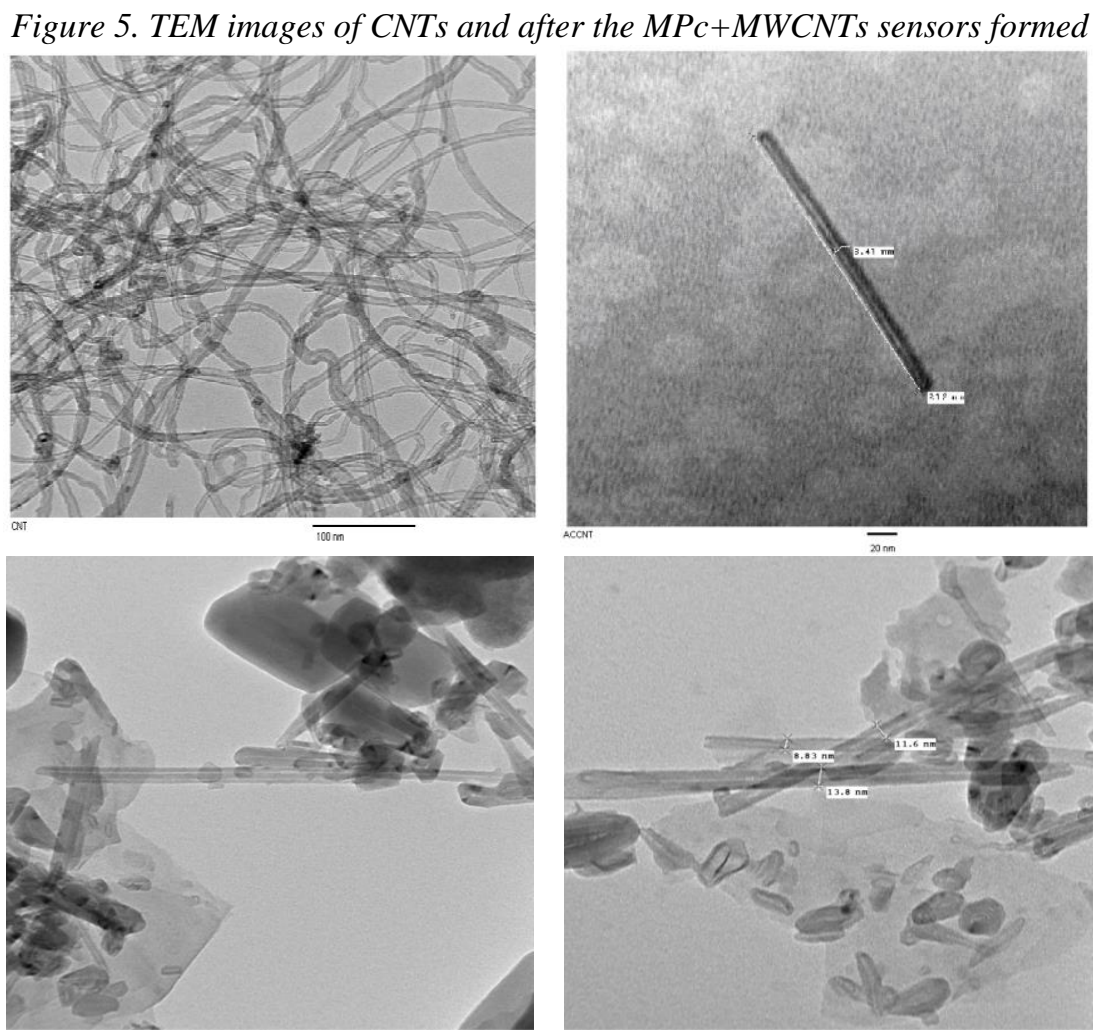

TEM studies on all samples are represented by Fig 5 (a-d) were performed on MWCNT and MWCNTs+MPcs. Fig 5a showes the MWCNTs structure morphology and Fig 5b shows the length around 200nm and diameter $8 \mathrm{~nm}$ for MWCNTs. In 5(c-d) images, Shows the composites morphology. TEM images confirmes the CuPc got anchored on the surface of MWCNTs.

\subsection{Sensing properties}

Since the absorption of organic vapour molecules affects the electrical conduction properties of the carbon nanotube surrounding medium, the change in electrical conductivity or resistance could be correlated to the concentration of absorbed vapour. The resistance of pure MPc, in gega ohm range at room temperature, is significantly decreased by inclusion of f-MWCNT. The Average resistance at room temperature decreases as the percentage of f-MWCNT containing MPc/ fMWCNT increases. This decrease in resistance could be attributed to the strong pi-pi electron/hydrogen bonding interaction between the surface functional groups of f-MWCNT and MPc. This in turn, is expected to increase the crystallinity of the molecular semiconductor and decrease its electric resistance. The response of pure MPc sensor toward chloroform vapors is appreciably poor due to its weak interaction with vapour molecule. In this paper, the sensing capability of MPc/f-MWCNT toward different concentrations $100 \mathrm{ppm}$ of chloroform vapor has been explored. The improvement of interfacial interaction can be achieved by the surfacefunctionalization of nanotube. The polar group on the nanotube surface increase the adsorption affinity of the electron-donor or acceptor gases and consequently offers better response. For the fabrication of nanocomposite based sensors, the interaction between the surface functional group 
of CNT and functional groups in the polymer chain can also promote the dispersion of the nanotube in the composites, The combination of organic semiconductor and CNT is an attractive route to fabricate a new sensor material having fast response, high sensitivity, good selectivity and good reproducibility at ambient condition.

Table 1: Table for sensing behaviour of chloroform vapour for M-Pc and M-TPP nanocomposites.

\begin{tabular}{|c|l|l|l|l|l|}
\hline $\begin{array}{l}\text { Type of } \\
\text { Vapors }\end{array}$ & $\begin{array}{l}\text { Initial } \\
\text { Resistance } \\
(\Omega)\end{array}$ & $\begin{array}{l}\text { Final } \\
\text { Resistance } \\
(\Omega)\end{array}$ & $\begin{array}{l}\text { \% Increase/ Decrease in } \\
\text { Resistance } \Delta R / R 0 X 100\end{array}$ & $\begin{array}{l}\text { Response } \\
\text { Time (sec) }\end{array}$ & $\begin{array}{l}\text { Recovery } \\
(\mathrm{sec})\end{array}$ \\
\hline $\begin{array}{c}\mathrm{Cu}- \\
\mathrm{TPP}\end{array}$ & 641 & 655 & $2.2 \%$ & $3 \mathrm{~min}$ & $4 \mathrm{~min}$ \\
\hline $\begin{array}{c}\mathrm{Co}- \\
\mathrm{TPP}\end{array}$ & 157.5 & 162 & $2.9 \%$ & $2.5 \mathrm{~min}$ & $2 \mathrm{~min}$ \\
\hline $\mathrm{Cu}-\mathrm{Pc}$ & 157 & 144 & $-8.3 \%$ & $2 \mathrm{~min}$ & approx $3 \mathrm{hour}$ \\
\hline $\mathrm{Co}-\mathrm{Pc}$ & 917 & 860 & -6.2 & $1 \mathrm{~min}$ & approx 1 hour \\
\hline
\end{tabular}

The sensors made from composites comprising of f-MWCNT and M-Pc ( $\mathrm{Cu}$ and $\mathrm{Co}$ ) shows 8.3 and $6.2 \%$ decrease on the other hand M-TPP $(\mathrm{Cu}$ and $\mathrm{Co}$ ) based sensor shows 2.2 and $2.9 \%$ increase in resistance on the exposure to chloroform. The two paired sensors made from composites of f-MWCNT with CuPc and CuTPP composites show opposite change in their resistance on exposure to chloroform vapour. While for the same sensors $\mathrm{Cu}-\mathrm{Pc}$ shows different sensing results for the $\mathrm{CCl} 4, \mathrm{Cl} 2$ (water) and $\mathrm{CH}_{2} \mathrm{Cl}_{2}$ while for Chloroform the resistance decreases. This contrasting behaviour in the electrical response of the M-Pc sensors has been exploited to provide unambiguous signature of chloroform in ambient environment (Saxena at el 2015). Fig 6c shows that chlorine water has slightly increase in resistance. 
Figure 6: (A) Opposite sensing behaviour for $\mathrm{CCl}_{4}$ and $\mathrm{CHCl}_{3}$ with the composite $C u P c+f-M W C N T s$ (B) Opposite sensing behaviour for $\mathrm{CCl}_{4}$ and $\mathrm{CHCl}_{3}$ with the composite CoTPP+f-MWCNTs
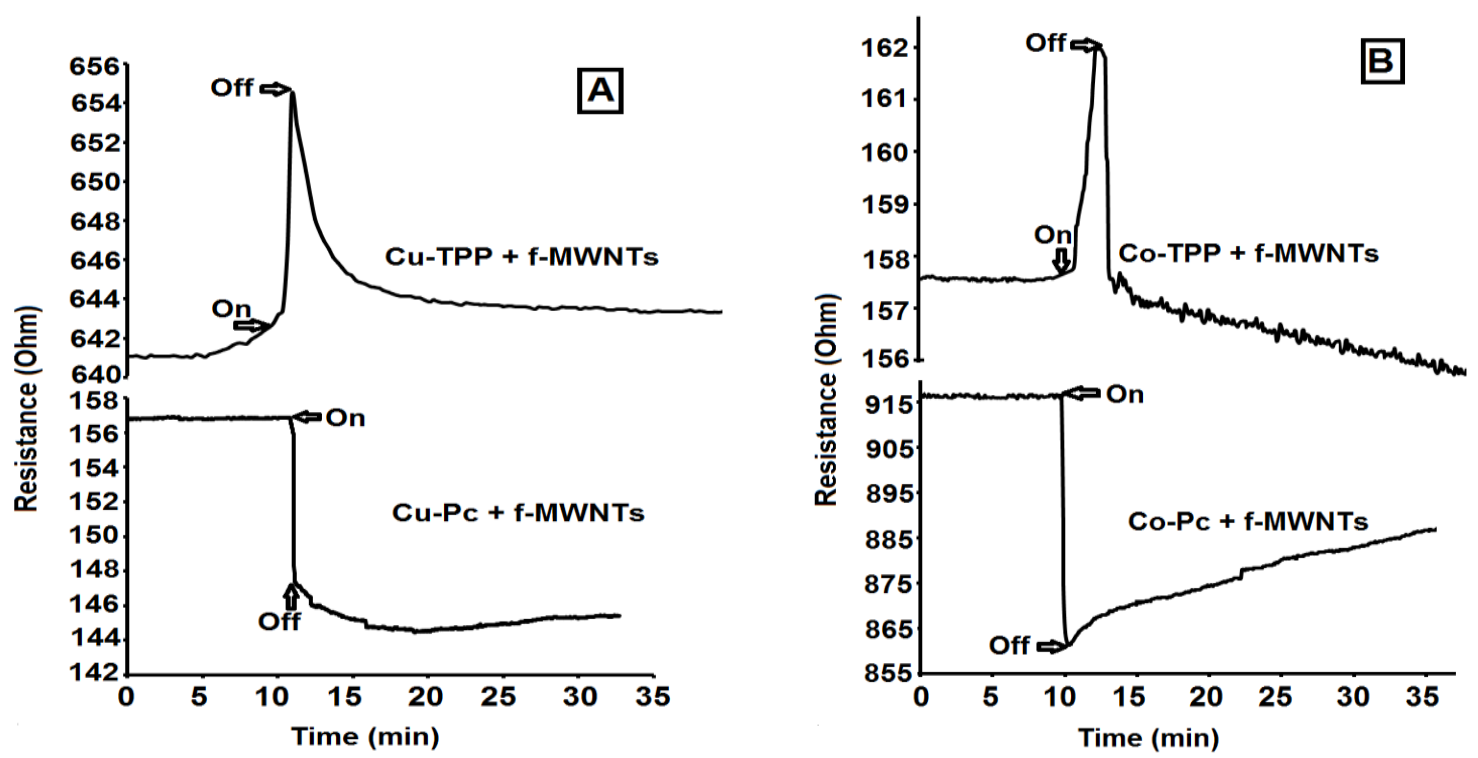

Figure 6 (C) Opposite sensing behaviour for $\mathrm{CCl}_{4}, \mathrm{CH}_{2} \mathrm{Cl}_{2}, \mathrm{Cl}_{2}$ and $\mathrm{CHCl}_{3}$ with the composite $\mathrm{CuPc}+\mathrm{f}-\mathrm{MWCNTs}$

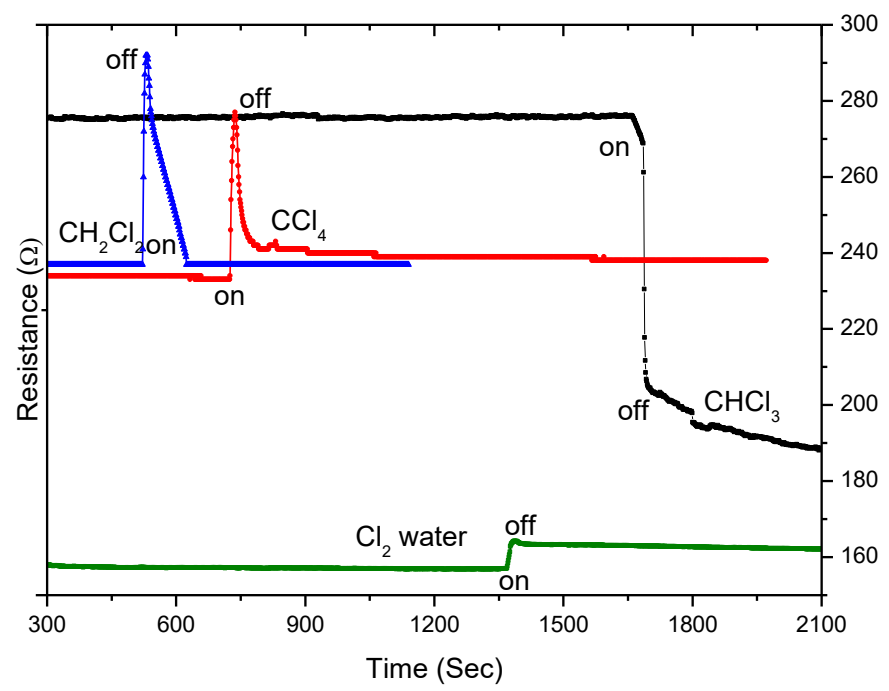

\section{Conclusion}

In this paper, we present room temperature operation, high sensitivity, low detection limit, fast response/recovery and excellent selectivity are desirable for a wide range of chloroform sensing application. A combination of sensors made from composites of $\mathrm{Co}-\mathrm{Pc}$ and $\mathrm{Cu}-\mathrm{Pc}$ with MWCNTs has been found to show opposite conductivities to chloroform and $\mathrm{CCl}_{4}, \mathrm{CH}_{2} \mathrm{Cl}_{2}$ and 
$\mathrm{Cl}_{2}$ water vapour. This unusual behaviour makes this sensor as a reliable method to selectively. The sensor response toward chloroform was tested, and the results show that the pair of nanocomposite has good response and the sensor is able to desorb attached species very efficiently, and yield very promising result. (Malisa et al1998 John Wiley \& Sons, Inc.)

\section{Ackowledgement}

Authors would like to thank SERB-DST, New Delhi for providing funding support for this work. First author would also like to thank toProf. A.L.Verma for providing information time to time related to this research work.

\section{Reference}

[1] Kylin B, Reichard H, Sumegi I, and Ylliner S. (1963). Hepatotoxicity of inhaled trichloroethylene, tetrachloroethylene and chloroform. Single exposure. Acta Pharmacol Toxicol 20, 16-26.

[2] Fan A. M. (2005) European Union Risk Assessment Report of chloroform, 1, 561-565, Elsevier Inc.

[3] Jones W. M., Margolis G. and Stephen C. R. (1958). Hepatotoxicity of inhalation anesthetic drugs. Anesthesiology, 19, 715-723.

[4] Ikatsu H. and Nakajima T. (1992). Hepatotoxic interaction between carbon tetrachloride and chloroform in ethanol treated rats. Arch Toxicol 66(8), 580-586.

[5] Kanada M, Miyagawa M, Sato M, Hasegawa H and Honma T, (1994). Neurochemical profile of effects of 28 neurotoxic chemicals on the central nervous system in rats (1) effects of oral administration on brain contents of biogenic amines and metabolites. Ind Health 32, 145-164.

[6] Sharma S., Nirkhe C., Pethkar S. and Athawale A. A., (2002). Chloroform vapour sensor based on copper/polyaniline nanocomposite, Sens. Actuator B-Chem. 85 (1-2), 131-136.

[7] Rahman M. M., Balkhoyor H. B., Asiri A. M. and Sobahi T. R., (2016). Development of selective chloroform sensor with transition metal oxide nanoparticle/multi-walled carbon nanotube nanocomposites by modified glassy carbon electrode, J. Taiwan Inst Chem E, 66, 336-346.

[8] Sheng K, Lu H, Sun A, Wang Y, Liu Y, Chen F, BianW, Li Y, Kuang R, Sun D, (2019). A naked-eye colorimetric sensor for chloroform, Chin. Chem. Lett., 30(4), 895-898.

[9] Abraham J. K., Philip B., Witchurch A., Varadan V. K. and Reddy C. C., (2004). A compact wireless gas sensor using a carbon nanotube/PMMA thin film chemiresistor, Smart Mater. Struct. $13,1045-1049$.

[10] Feller J. F., Gatt N., Kumar B. and Castro M. (2014). Selectivity of Chemoresistive Sensors Made of Chemically Functionalized Carbon Nanotube Random Networks for Volatile Organic Compounds (VOC), Chemosensors, 2, 26-40.

[11] Sharma A. K., Mahajan A., Bedi R. K., Kumar S., Debnathc A.K., Aswal D.K., (2018). Non-covalently anchored multi-walled carbon nanotubes with hexa-decafluorinated zinc phthalocyanine as ppb level chemiresistive chlorine sensor, App. Surf. Sci., 427, 202-209.

[12] Mondal K., Halder P., Gopalan G., Sasikumar P., Radhakrishnan K. V., Das P. (2019). Chloroform as a CO surrogate: applications and recent developments, Org. Biomol. Chem. 17, 5212-5222.

[13] Giordano M., Russo M., Cusano A., Mensitieri G. (2005). An high sensitivity optical sensor for chloroform vapours detection based on nanometric film of $\delta$-form syndiotactic polystyrene, Sens. Actuator B-Chem., 107, 140-147. 
[14] Fong J. K., Pena J. K., Xue Z. L., Alam M. M., Sampathkumaran U. and Goswami K., (2015). Optical Sensors for the Detection of Trace Chloroform, Anal. Chem., 87, 1569-1574.

[15] Jo WK, Weisel CP, Lioy PJ. (1990). Routes of chloroform exposure and body burden from showering with chlorinated tap water, Risk Anal, 10(4), 575-580.

[16] Philip B., Abraham J. K., Chandrasekhar A. and Varadan V. K. (2003), Carbon nanotube/PMMA composite thin films for gas-sensing applications, Smart Mater. Struct. 12 (2003) 935-939.

[17] Sharma A. K., Mahajan A., Bedi R. K., Kumar A. S., Debnathc A. K. and Aswald D. K. (2017). CNTs based improved chlorine sensor from noncovalently anchored multi-walled carbon nanotubes with hexa-decafluorinated cobalt Phthalocyanines, RSC Adv., 7, 49675-49683.

[18] Kanan S. M., El-Kadri O. M., Imad A. Yousef A. and Kanan M. C. (2009). Semiconducting Metal Oxide Based Sensors for Selective Gas Pollutant Detection Sensors, 9, 8158-8196.

[19] Kar P. and Choudhury A. (2013). Carboxylic acid functionalized multi-walled carbon nanotube doped polyaniline for chloroform sensors, Sens. Actuator B-Chem., 183, 25- 33.

[20] Verma A. L., Saxena S., Saini GSS, Gaur V. and Jain V.K., (2011). Hydrogen Peroxide Vapor Sensor Using Metal-Phthalocyanine Functionalized Carbon Nanotubes, Thin Solid Films 519, 8144-8148.

[21] Léger L., Moreau E., and Touchard G. G., (2002). Effect of a DC Corona Electrical Discharge on the Air flow Along a Flat Plate" IEEE Trans. Ind. Appl., 38(6), 1478-1485.

[22] Saxena S. and Verma A. L., (2014). Metal-Tetraphenylporphyrin Functionalized carbon nanotube composites as sensors for BTX vapors, Adv. Mat. Lett. 5(8), 472-478.

[23] Pan H., Liu L., Guo Z.X., Dai L., Hang F., Zhu D., Czerw R., Caroll D. L., (2003). Carbon Nanotubols from Mechanochemical Reaction, Nano Lett., 3, 29-32.

[24] Wang J., Li M., Shi Z., Li N., Gu Z., (2002). Direct Electrochemistry of Cytochrome c at a Glassy Carbon Electrode Modified with Single-Wall Carbon Nanotubes, Anal. Chem., 74 19931997.

[25] Yu X., Chattopadhyay D., Galeska I., Papadimitrakopoulos F., Rusling J. F., (2003). Peroxidase activity of enzymes bound to the ends of single-wall carbon nanotube forest electrodes, Electrochem. Commun., 5, 408-411.

[26] Saxena S., Saini G S S and Verma A. L., (2015). Co-TPP functionalized carbon nanotube composites for detection of nitrobenzene and chlorobenzene vapours, Bull. Mat. Sci., 38, 443449.

[27] Chiappero M. S., Arguello G. A. (1998). Deactivation of $\mathrm{I}\left({ }^{2} \mathrm{P}_{1 / 2}\right)$ by $\mathrm{CH}_{3} \mathrm{Cl}, \mathrm{CH}_{2} \mathrm{Cl}_{2}$, $\mathrm{CHCl}_{3}, \mathrm{CCl}_{3} \mathrm{~F}$, and $\mathrm{CCl}_{4}$, Int. J. Chem. Kinet., 30(11), 799-803. 